\title{
Histórias em quadrinhos e ensino de História
}

comics and History teaching

Douglas Mota Xavier de Lima*

\section{REsumo}

Os últimos anos têm sido marcados pela ampliação da presença de Histórias em Quadrinhos (HQs) no ambiente escolar, movimento que se manifesta, em especial, no Plano Nacional Biblioteca na Escola (PNBE). A presença das HQs tem criado novos desafios aos educadores, mostrando a necessidade de compreensão da linguagem e mesmo da variedade de obras disponíveis. $\mathrm{O}$ artigo discute a inserção das HQs no ambiente escolar e problematiza a linguagem dos quadrinhos no ensino de História, apresentando sugestões de obras e discussões possíveis para a área.

Palavras-chave: história em quadrinhos; História; ensino de História.

\begin{abstract}
The last years have been marked by the enlargement of the Comics in the school environment, a movement that occurs, especially, in the Library at School National Plan (PNBE). The presence of Comics has been creating new challenges to the educators, such as the need of understanding the language and being aware of the variety of works which are available. The article discusses the insertion of Comics in the school environment and problematizes the language of comics in the History teaching, presenting suggestions of works and possible discussions for the area.

Keywords: comics; History; History teaching.
\end{abstract}

Infelizmente, é preciso admitir que os quadrinhos estão em crise. Desde o início de 1974, com o surgimento da crise de energia, de petróleo e, principalmente, do papel, os quadrinhos atravessam uma crise sem precedentes, desde o advento da tevê. O que é uma pena, pois os comics surgiram no fim do século passado, no mesmo ano que o cinema. Mas, enquanto a invenção dos Lumière foi saudada como a sétima arte desde o princípio, com Méliès, Griffith, Eisenstein e Chaplin, os quadrinhos foram ignorados ... Que os quadrinhos superem essa crise e consigam continuar a satirizar e criticar todo o mundo e seu habitante mais criticável: o homem.

Moya, 1986

* Doutor em História pela Universidade Federal Fluminense (UFF). Professor Adjunto da Universidade Federal do Oeste do Pará (Ufopa). Santarém, PA, Brasil. douglas.mxl@ufopa.edu.br 
As primeiras páginas de A História das histórias em quadrinhos, de Álvaro Moya, expressam o difícil cenário vivido pela arte em meados dos anos 1980. A recuperação de tais palavras permite constatar as profundas mudanças que ocorreram nos quadrinhos nas três décadas que nos distanciam da redação desse texto. Frente aos números da indústria das Histórias em Quadrinhos, aos títulos lançados anualmente e ao crescente espaço que a nona arte vem conseguindo na educação, é possível considerar que os desejos de Moya em relação ao futuro das histórias em quadrinhos parecem ter se realizado.

Tendo em vista esse cenário, o presente artigo busca refletir sobre a relação entre Histórias em Quadrinhos (HQs) e Ensino de História. Para tal, inicialmente, concentra-se a atenção no processo de incorporação dos quadrinhos no ambiente escolar, destacando, em seguida, a linguagem dos quadrinhos no ensino de História e como as HQs podem configurar uma nova escrita da História. Por fim, apresentam-se alguns títulos acompanhados de sugestões de discussão no ensino de História.

\section{As HQs NO AMBIENTE ESCOLAR}

Enfrentando as críticas e as resistências desenvolvidas ao longo do século passado, gradativamente os quadrinhos deixaram de ser compreendidos como leitura exclusiva de crianças para serem entendidos como forma de entretenimento de diversos públicos. No que concerne ao campo da educação, o movimento de aceitação e incorporação dos quadrinhos foi ainda mais significativo, concentrando-se, em especial, em finais do século XX. De acordo com Waldomiro Vergueiro, tal processo acentuou-se durante a década de $1970 \mathrm{com}$ publicações de quadrinhos com fins educativos, os quais ajudaram a firmar o entendimento de que as HQs podiam ser utilizadas para transmissão de conteúdos escolares (Vergueiro, 2014, p.19).

Desde os anos 1980 as análises relativas aos quadrinhos e ao saber histórico têm se ampliado no Brasil, merecendo destaque os trabalhos de Zélia Lopes da Silva, Marco Aurélio Pereira, Sônia Bide Luyten, Waldomiro Vergueiro e Paulo Ramos. Em Quadrinhos na Educação: da rejeição à prática (2009), Vergueiro e Ramos argumentam que a Lei de Diretrizes e Bases da Educação Nacional (LDB), de 1996, ao apontar para a necessidade de inserção 
de novas linguagens e manifestações artísticas nos ensinos fundamental e médio, ampliou as possibilidades de utilização dos quadrinhos no ensino, mas foram os Parâmetros Curriculares Nacionais (PCNs), lançados em 1997, que colocaram as HQs diretamente nas salas de aula.

Consoante os autores, igualmente significativa para a promoção dos quadrinhos no ensino foi a publicação de HQs pelo Programa Nacional Biblioteca na Escola (PNBE), em 2006. Criado em 1997, o Programa foi responsável pela compra de obras e por sua distribuição em escolas de ensino fundamental e médio, pautando-se, prioritariamente, na distribuição de livros literários. Porém, em 2006, pela primeira vez foram incluídas obras em quadrinhos. Nesse ano foram comprados 225 títulos, dos quais dez eram histórias em quadrinhos.

As aquisições de 2006 e de 2008 pautaram-se pela orientação de que os quadrinhos são um gênero literário e pela ênfase em adaptações de obras clássicas da literatura universal. Outro aspecto ressaltado por Vergueiro e Ramos é a existência de uma interpretação do governo federal de que os quadrinhos são mais indicados à realidade do ensino básico, manifesta na seleção e na distribuição das HQs pelo ensino fundamental e médio. Mesmo com a aquisição de obras para o Ensino Médio a partir de 2009, a crítica trazida pelos autores é que, por mais que sejam indiscutíveis os avanços alcançados pela inclusão dos quadrinhos nos PNBE desde 2006, as obras continuam a ser consideradas "ferramentas" que permitem ao estudante alcançar outras formas de leitura, criando, assim, uma hierarquização de leitura. Defendem que é necessário "que o programa se afaste da interpretação de que quadrinhos são um gênero literário e que passem a ser avaliados pelo conteúdo que apresentam, bom ou ruim, como uma linguagem autônoma" (Vergueiro; Ramos, 2009).

Em linhas gerais, a orientação do programa continuou a favorecer as adaptações literárias; no entanto, Paulo Ramos considera que, mesmo enfrentando resistências em 2009 relativas às obras de Will Eisner, o PNBE passou a agregar um número cada vez maior de obras em quadrinhos, tanto para o ensino fundamental, como para o ensino médio e a educação de jovens e adultos (Ramos, 2012, p.223-240). Tal acréscimo também está relacionado ao aumento dos recursos do programa, conforme se observa na Tabela 1. 
Tabela 1 - Investimento no PNBE (2006-2013)

\begin{tabular}{cc}
\hline & Investimento \\
\hline 2006 & $\mathrm{R} \$ 46.509 .183,56$ \\
\hline 2008 & $\mathrm{R} \$ 65.283 .759,50$ \\
\hline 2009 & $\mathrm{R} \$ 74.447 .584,30$ \\
\hline 2010 & $\mathrm{R} \$ 48.766 .696,45$ \\
\hline 2011 & $\mathrm{R} \$ 70.812 .088,00$ \\
\hline 2012 & $\mathrm{R} \$ 81.437 .946,11$ \\
\hline 2013 & $\mathrm{R} \$ 86.381 .384,21$ \\
\hline
\end{tabular}

Fonte: PNBE, 2014, p.10.

Não conhecemos trabalhos mais detalhados sobre as HQs no PNBE entre 2010 e 2014, assim, propomos um breve levantamento das obras inseridas no programa em 2014. Destaca-se que nesta edição o governo publicou guias que acompanham o material selecionado para a educação infantil, as séries iniciais do ensino fundamental e para a educação de jovens e adultos. As HQs aparecem incluídas na categoria "Livros de Imagens e Livros de histórias em quadrinhos", e os títulos adquiridos pelo programa encontram-se detalhados no Quadro 1.

Quadro 1 - Categoria - Livros de Imagens e

Livros de histórias em quadrinhos

\begin{tabular}{|c|c|c|c|}
\hline Título & Editora & $\mathrm{T} / \mathrm{A} / \mathrm{I}$ & Categoria escolar \\
\hline Você e Eu & $\begin{array}{l}\text { Livros da } \\
\text { Matriz }\end{array}$ & Maggie Maino (T/I) & $\begin{array}{l}\text { Educação infantil } \\
\left(4^{\circ} \text { e } 5^{\circ} \text { anos }\right)\end{array}$ \\
\hline A visita & $\begin{array}{c}\text { Farol } \\
\text { Literário }\end{array}$ & Lúcia Hiratsuka (T/I) & $\begin{array}{l}\text { Educação infantil } \\
\left.\text { ( } 4^{\circ} \text { e } 5^{\circ} \text { anos }\right)\end{array}$ \\
\hline Rapunzel & $\begin{array}{l}\text { Mundo } \\
\text { Mirim }\end{array}$ & $\begin{array}{l}\text { Jacob Grimm e } \\
\text { Wilhelm Grimm }(\mathrm{T}) \\
\text { Thaís Linhares }(\mathrm{A} / \mathrm{I})\end{array}$ & $\begin{array}{l}\text { Educação infantil } \\
\qquad\left(4^{\circ} \text { e } 5^{\circ} \text { anos }\right)\end{array}$ \\
\hline $\begin{array}{c}\text { Lá vem o } \\
\text { homem do saco }\end{array}$ & $\begin{array}{c}\text { Ed. } \\
\text { PUC-Rio }\end{array}$ & Regina Rennó (T/I) & $\begin{array}{l}\text { Educação infantil } \\
\qquad\left(4^{\circ} \text { e } 5^{\circ} \text { anos }\right)\end{array}$ \\
\hline Vai e vem & Gaivota & Laurent Cardon (T/I) & $\begin{array}{l}\text { Ensino fundamental } \\
\text { (anos iniciais) }\end{array}$ \\
\hline
\end{tabular}


continuação

\begin{tabular}{|c|c|c|c|}
\hline $\begin{array}{c}\text { Histórias da Carolina: } A \\
\text { menina sonhadora que } \\
\text { quer mudar o mundo }\end{array}$ & Globo livros & Ziraldo (T/I) & $\begin{array}{c}\text { Ensino fundamental } \\
\text { (anos iniciais) }\end{array}$ \\
\hline E a mosca foi pro espaço & $\begin{array}{c}\text { Escala } \\
\text { Educacional }\end{array}$ & $\begin{array}{l}\text { Renato Moriconi } \\
\qquad(\mathrm{T} / \mathrm{I})\end{array}$ & $\begin{array}{l}\text { Ensino fundamental } \\
\text { (anos iniciais) }\end{array}$ \\
\hline $\begin{array}{l}20.000 \text { léguas } \\
\text { submarinas }\end{array}$ & Nemo & $\begin{array}{c}\text { João Marcos }(\mathrm{T}) \\
\text { Will (I) }\end{array}$ & $\begin{array}{l}\text { Ensino fundamental } \\
\text { (anos iniciais) }\end{array}$ \\
\hline Os pássaros & Editora 34 & $\begin{array}{c}\text { Albertine Zullo e } \\
\text { Germano Zullo (T/I) }\end{array}$ & $\begin{array}{l}\text { Ensino fundamental } \\
\text { (anos iniciais) }\end{array}$ \\
\hline Cena de rua & Gaivota & Laurent Cardon (T/I) & $\begin{array}{l}\text { Ensino fundamental } \\
\text { (anos iniciais) }\end{array}$ \\
\hline Certos dias & $\begin{array}{c}\text { Casa } \\
\text { amarelinha }\end{array}$ & María Wernicke (T/I) & $\begin{array}{l}\text { Ensino fundamental } \\
\text { (anos iniciais) }\end{array}$ \\
\hline $\begin{array}{c}\text { Os doze trabalhos de } \\
\text { Hércules }\end{array}$ & Globo kids & $\begin{array}{l}\text { Denise Ortega (A) } \\
\text { Luiz Podavin (I) }\end{array}$ & $\begin{array}{l}\text { Ensino fundamental } \\
\text { (anos iniciais) }\end{array}$ \\
\hline $\begin{array}{c}\text { Boule \& Bill: semente } \\
\text { de Cocker }\end{array}$ & Nemo & $\begin{array}{c}\text { Laurent Verron (T) } \\
\text { Roba (I) }\end{array}$ & $\begin{array}{c}\text { Ensino fundamental } \\
\text { (anos iniciais) }\end{array}$ \\
\hline 1 Real & $\begin{array}{c}\text { Edições } \\
\text { Jogo de } \\
\text { Amarelinha }\end{array}$ & $\begin{array}{l}\text { Federico Delicado } \\
\text { Gallego }(\mathrm{T} / \mathrm{I})\end{array}$ & $\begin{array}{c}\text { Educação de Jovens } \\
\text { e Adultos }\end{array}$ \\
\hline Dom Casmurro & Devir & $\begin{array}{c}\text { Felipe Greco (A) } \\
\text { Mario Cau (I) }\end{array}$ & $\begin{array}{c}\text { Educação de Jovens } \\
\text { e Adultos }\end{array}$ \\
\hline $\begin{array}{l}\text { Quando Maria } \\
\text { encontrou João }\end{array}$ & Singular & Rui de Oliveira (T/I) & $\begin{array}{c}\text { Educação de Jovens } \\
\text { e Adultos }\end{array}$ \\
\hline O voo da asa branca & Prumo & Soud (T/I) & $\begin{array}{c}\text { Educação de Jovens } \\
\text { e Adultos }\end{array}$ \\
\hline Lenço branco & $\begin{array}{l}\text { Pequena } \\
\text { Zahar }\end{array}$ & $\begin{array}{c}\text { Viorel Boldis (T) } \\
\text { Antonella Toffolo (I) }\end{array}$ & $\begin{array}{c}\text { Educação de Jovens } \\
\text { e Adultos }\end{array}$ \\
\hline
\end{tabular}

Fonte: PNBE - Guia 2, 2014. Legenda: T - Texto; I - Ilustração; A - Autoria.

Em linhas gerais, o guia que acompanha a publicação do PNBE promove o que Vergueiro (2005) argumentava como a necessária "alfabetização na 
linguagem dos quadrinhos". Entre os elementos que o texto destaca estão: "Trama”, "Personagens", "Objetos de uma trama ilustrada", “Tempo e movimento", "Enquadramento" - no qual se detalham itens como: plano geral, plano conjunto, plano médio, plano americano, plano aproximado, close e plano de detalhe -, "Profundidade" e "Ponto de vista".

Para além desse aspecto da incorporação dos quadrinhos no ambiente escolar, cabe lembrar outros fatores que também contribuíram para tal cenário. Primeiramente, a crescente presença dos quadrinhos no meio acadêmico (Vergueiro, 2005) e o avanço da promoção de encontros e outras atividades relacionadas ao universo HQ. Em segundo lugar, ações como a da administração da cidade de São Vicente (SP), que publica, desde 1998, HQs para a utilização em sala de aula (Tatsubô, 2005), acompanhadas da já citada diversificação dos títulos disponíveis no mercado.

No intuito de finalizar este item recuperam-se, como exemplo, algumas potencialidades dos quadrinhos no ensino. Vergueiro considera que: as HQs aumentam a motivação dos estudantes para o conteúdo das aulas, aguçando a curiosidade e desafiando seu senso crítico; a interligação do texto com a imagem, presente nas HQs, amplia a compreensão de conceitos de uma forma que qualquer um dos códigos, isoladamente, teria dificuldades para atingir; as HQs versam sobre os mais diferentes temas, sendo facilmente aplicáveis em qualquer área, além de apresentarem uma linguagem mais assimilável; a inclusão dos quadrinhos na sala de aula possibilita ao estudante ampliar seu leque de meios de comunicação, incorporando a linguagem gráfica à linguagem oral e escrita, que normalmente utiliza; os quadrinhos auxiliam no desenvolvimento do hábito de leitura; os quadrinhos enriquecem o vocabulário dos estudantes; o caráter elíptico da linguagem dos quadrinhos obriga o leitor a pensar e imaginar, tornando as HQs especialmente úteis para exercícios de compreensão de leitura e como fontes para estimular os métodos de análise e síntese de mensagens; os quadrinhos têm caráter globalizador, trazem temáticas que têm condições de ser compreendidas sem necessidade de um conhecimento prévio específico ou da familiaridade com o tema; os quadrinhos podem ser utilizados em qualquer nível escolar e com qualquer tema.

Tal como o autor, acreditamos que esses elementos constituem apenas exemplos das potencialidades do aproveitamento dos quadrinhos no ensino. 
Com base no que foi exposto, passamos a considerações sobre o caso específico da História.

\section{Os Quadrinhos no Ensino de História}

A utilização das HQs no ensino de História tem se afirmado lentamente nas últimas décadas, em especial em decorrência do movimento historiográfico de ampliação da noção de fontes e pela abertura do espaço escolar para a utilização de novas linguagens (Rocha, 2015). Além disso, convém destacar que desde meados do século passado é comum encontrar histórias em quadrinhos direcionadas ao trato de eventos históricos com cunho educativo, o qual, por vezes, revela ligação profunda com o regime político em vigência no país de origem dos quadrinhos (cf. Vergueiro, 2014, p.18; Nebiolo, 1976).

A problematização sobre o uso das HQs no ensino de História no Brasil não constitui novidade, podendo ser encontrada em artigos, dissertações e trabalhos de conclusão de curso. Não obstante, nota-se a ausência de estudos mais amplos que envolvam a própria narrativa histórica formulada através da linguagem dos quadrinhos ou que explorem teoricamente experiências de práticas de ensino com HQs. ${ }^{1}$ Nesse quadro, destaca-se o texto de Túlio Vilela (2014), "Os Quadrinhos na aula de História”, presente na obra Como usar as histórias em quadrinhos em sala de aula, como norteador das discussões iniciais do presente tópico.

Vilela levanta diferentes maneiras ou enfoques para a utilização das HQs no ensino de História: para ilustrar ou fornecer uma ideia de aspectos da vida social de comunidades do passado; para serem lidos e estudados como registros da época em que foram produzidos; para serem utilizados como ponto de partida de discussões de conceitos importantes para a História. Na sequência do texto o autor concentra-se em demonstrar, tomando como base o exemplo de Asterix, que tais enfoques podem ser trabalhados numa mesma história em quadrinhos, permitindo que o professor explore diferentes aspectos do material analisado.

Em outro momento do capítulo, Vilela destaca que apesar de suas especificidades, as HQs também podem ser problematizadas a partir de critérios utilizados para outros documentos. Destarte, levanta interrogações como: quem são os autores? Quando e onde foi produzida? Por quem fala? A quem se 
destina? Qual é a sua finalidade? Do mesmo modo, o autor lembra que muitas histórias em quadrinhos colocam o historiador em contato com o problema da memória - especialmente no caso das obras autobiográficas -, do anacronismo e da verossimilhança, elementos recorrentes na prática historiográfica.

Partindo dos elementos expostos por Vilela, cabe refletir sobre o papel e a forma de as HQs tratarem de aspectos do passado. Como lembra António Cagnin, assim como o cinema e outros sistemas de imagens, as histórias em quadrinhos narram fatos e feitos, sendo em essência uma história em imagens. Dessa maneira, coloca-se o dilema de trabalhar com fatos históricos mediante uma narrativa ficcional. Tal problemática aparece de forma mais incisiva nos estudos sobre cinema e história, sendo crescentes as pesquisas que procuram superar a questão das representações imprecisas do passado nos filmes. A título de exemplo, citamos algumas considerações de Robert Rosenstone.

Para esse autor, os filmes, minisséries e documentários são gêneros cada vez mais importantes em nossa relação e entendimento do passado. Ele considera que a história nas páginas impressas e a história na tela são semelhantes em pelo menos dois aspectos: "referem-se a acontecimentos, momentos e movimentos reais do passado e, ao mesmo tempo, compartilham do irreal e do ficcional". Uma das perguntas centrais a que Rosenstone se propõe responder é: "onde os filmes se situam em relação a outros tipos de discurso histórico, o que os filmes históricos transmitem do passado, se é que transmitem algo, e como o fazem" (Rosenstone, 2015, p.14-21).

Relacionando os questionamentos de Rosenstone com o universo das HQs, consideramos que estas não apenas ilustram a realidade, elas a constroem a partir de uma linguagem própria - como arte sequencial, por definição de Will Eisner (1999) - produzida num determinado contexto histórico. Assumem papel importante na construção do conhecimento histórico, o qual está associado ao saber acadêmico ou científico e aos meios de comunicação de massa, como o cinema e os próprios quadrinhos. Para esse feito, Alexandre Barbosa defende que:

Elas trabalham com a ficção, mas carregam em si todos os elementos que constatam a realidade, tanto no discurso da escrita como no discurso visual.

O autor dos quadrinhos - principalmente aquele que trabalha com os chamados quadrinhos históricos - remete o leitor a documentos que são tidos como verda- 
deiros, por uma visão subjetiva, que é aquela dada pelo artista; dessa forma, ele constrói a cada momento uma nova história, com um olhar cotidiano, influenciado pelos novos estereótipos ou por novos ícones da cultura de massa. (Barbosa, 2009, p.106)

$\mathrm{O}$ autor avança em seus argumentos demonstrando que os quadrinhos trabalham os conceitos que servem como parâmetros de realidade do indivíduo, atualizando-os ou refletindo o pensamento de uma sociedade em determinado momento histórico, sendo a informação veiculada pelas HQs aceita como "parâmetro de realidade". Barbosa ainda defende que: "Em um determinado momento histórico, a ficção histórica também pode nos mostrar muito mais do sentimento de um grupo ou grupos do que o registro de um chamado 'documento oficial'” (Barbosa, 2009, p.107).

Dessa maneira, afirma-se que as HQs ampliam e constroem nosso conhecimento histórico e que as concepções sobre o passado e a sociedade presentes na linguagem dos quadrinhos podem ser integradas a outras leituras de obras eruditas e acadêmicas (Bonifácio; Cerri, 2005, p.3). Além disso, percebe-se que esse conjunto de problemas não envolve apenas um gênero de HQs, podendo ser aplicado a obras de diferentes características, como: quadrinhos biográficos, literatura em quadrinhos, quadrinhos de humor, mangás e quadrinhos de aventura (Vergueiro; Ramos, 2009). Para explorar tais posicionamentos, cabe observamos algumas histórias em quadrinhos nacionais e estrangeiras.

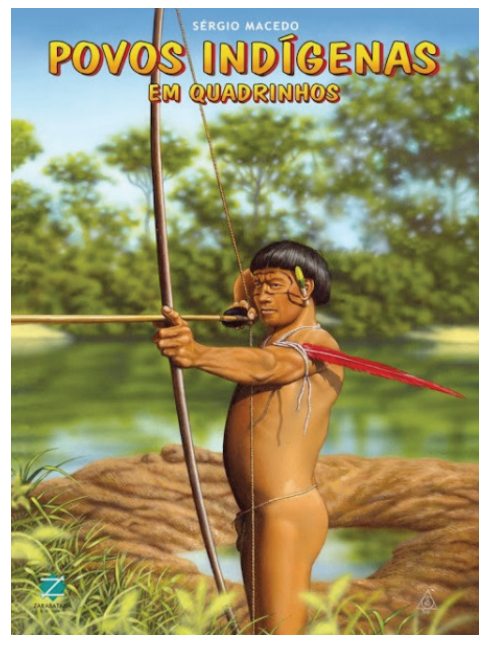

Figura 1 - Capa do álbum Povos Indígenas (2012), de Sérgio Macedo. 
Em primeiro lugar, partindo do contato direto com os povos indígenas, em especial do período que permaneceu na aldeia Kayapó Metuktire, no Mato Grosso, Sérgio Macedo publicou dois trabalhos relacionados aos índios brasileiros, Xingu (2008) e Povos indígenas (2012). Marcada por traços realistas e pela preocupação em dar espaço para as falas indígenas (por exemplo, pela narração de mitos e outras experiências comunitárias passadas por relatos orais), a obra expressa profunda pesquisa realizada pelo autor, permitindo que o professor de História disponha de um singular material para o estudo dos povos indígenas e de uma narrativa visual que aborda desde as primeiras comunidades indígenas anteriores à chegada dos portugueses aos contextos comunitários do século XX. Destaca-se que em Povos Indígenas Macedo aborda diferentes etnias, tais como Yanomami, Xavante, Suruí e Panará.

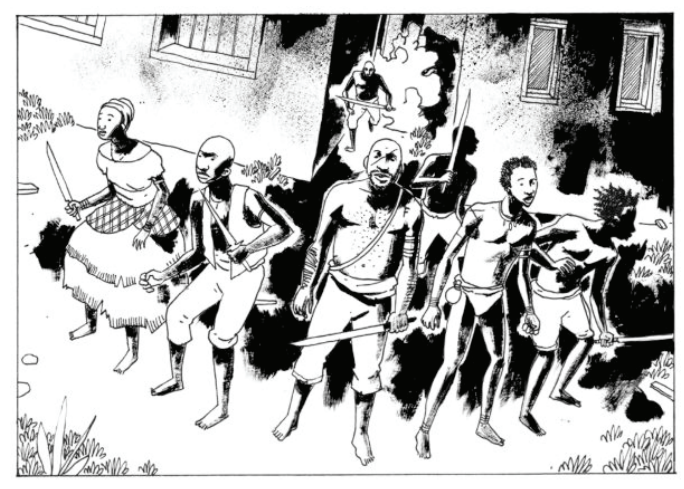

Figura 2 - Cena da HQ Cumbe (2014), de Marcelo D'Salete.

O segundo exemplo é a obra Cumbe (2014), de Marcelo D’Salete, com publicações internacionais em Portugal e na França. A história trata da escravidão, enfatizando a resistência negra e a opressão vivida no período colonial. D’Salete explora a linguagem usada pelos negros (apresentando um glossário ao final do texto), buscando referências claras em documentos históricos. Um dos elementos de maior destaque é a estruturação da narrativa do ponto de vista do escravo, contribuindo diretamente para a valorização das diferentes formas de resistência e, consequentemente, para a crítica da passividade da população escravizada. 
A partir das Leis 10.639/2011 e 11.645/2008, a temática trabalhada nas obras citadas tornou-se obrigatória nas escolas brasileiras. Nesse sentido, os trabalhos de Macedo e D'Salete constituem importante instrumento para a história afro-brasileira e indígena de nosso país, demonstrando que as HQs contribuem para o conhecimento histórico ampliando-o e construindo-o. Mais do que apenas tratar dos escravos coloniais ou dos povos indígenas, as histórias em quadrinhos em questão trazem tais grupos como protagonistas históricos, promovendo uma releitura do passado.

Como terceiro exemplo, cita-se O Paraíso de Zahra (2011), obra ficcional de Amir Soltani e Khalil Bendib, que se passa no Irã após as eleições de 2009. A história conta a busca familiar por Mehdi, um jovem que foi preso durante os protestos contra o governo e que sumiu nas mãos da repressão da República Islâmica. Apresentando a luta da mãe e do irmão do personagem na tentativa de encontrá-lo, a obra trata da história contemporânea do Irã, demonstrando que os conflitos existentes nessa sociedade envolvem relações pessoais, legais, políticas, religiosas e culturais. Nas palavras dos autores, "tentamos capturar e refletir a dignidade, humanidade, o amor e sofrimento do povo iraniano em O Paraíso de Zahra".

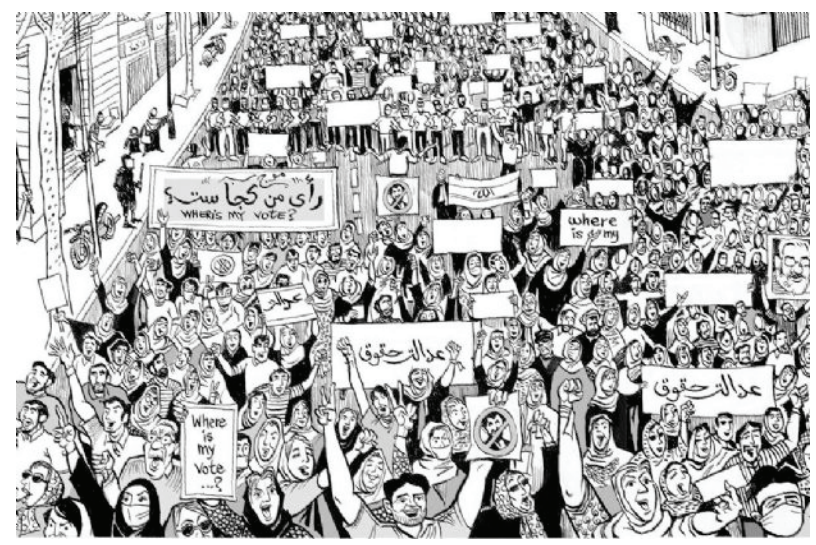

Figura 3 - Cena da HQ Paraíso de Zahra (2011), de Soltani e Bendib. 
Por fim, cita-se o conjunto da obra do jornalista Joe Sacco. Referência no chamado "jornalismo em quadrinhos", Sacco é o autor de obras como Palestina - uma nação ocupada (2000), Palestina - na Faixa de Gaza (2005), Área de segurança Gorazde - a Guerra na Bósnia Oriental (1992-1995) (2001), Uma história de Sarajevo (2005) e Notas sobre Gaza (2010), e ganhador de diferentes prêmios por seus trabalhos. Combinando reportagens com a reconstituição dos fatos por meio das imagens, Sacco aborda nesse conjunto de obras o conflito entre israelenses e palestinos, o desmembramento da Iugoslávia e as mortes nas "áreas de segurança” da ONU na Bósnia Oriental, dando espaço para a descrição dos locais e das pessoas comuns.

Esses dois últimos exemplos de quadrinhos internacionais traduzidos no Brasil reforçam a perspectiva de que as HQs ampliam e constroem nosso conhecimento do passado e, em ambos os casos, do presente. As histórias, seja na via ficcional de Soltani e Bendib, seja nos traços realistas do jornalismo de Joe Sacco, constituem relatos contemporâneos da realidade vivida no Irã, na Palestina e na Bósnia, realidade ainda distante do universo escolar na forma tradicional da História, mas que pode se tornar próxima pela utilização dos quadrinhos.

\section{Quadrinhos E Ensino de História - Algumas Possibilidades}

Como expusemos no início do artigo, nesta última etapa buscaremos apresentar alguns títulos e sugestões de ensino na área de História, articulando o conjunto de problemáticas apresentadas anteriormente.

Alix foi publicada pela primeira vez em 1948, na revista belga Tintin, sendo obra de Jacques Martin (1921-2010). Alix Graccus é um jovem gaulês que foi adotado pelos romanos. Ele vive no tempo de César e a obra traz uma detalhada representação dos elementos arquitetônicos, do vestuário, dos armamentos e dos costumes antigos. Alix teve 19 álbuns, abordando desde o Mediterrâneo ao Oriente, este representado pela China. A HQ não teve edição no Brasil, mas está disponível em língua portuguesa em edições de Portugal. Para a presente reflexão, usaremos o volume Garra Negra. 


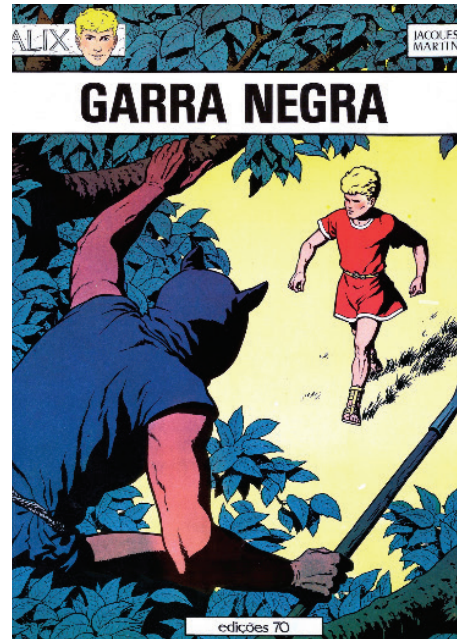

Figura 4 - Capa do volume Garra Negra, da HQ Alix, de Jacques Martin.

A aventura foi publicada pela primeira vez na revista Tintin entre dezembro de 1957 e fevereiro de 1959. Nesse mesmo ano foi publicada em álbum pelas Éditions du Lombard e, em 1965, pela Casterman. Em língua portuguesa a obra foi publicada pelas Edições 70 (1987) e pelas Edições Asa (2010). Chama atenção a existência de apenas duas histórias de Alix que envolvem o espaço africano subsaariano, sendo Garra Negra a única escrita e desenhada por Jacques Martin.

A história parte da tragédia de Ícara, pequena cidade costeira da África do Norte, ocorrida nas primeiras décadas do século I a.C. Os acontecimentos são narrados a Alix por Gallas, um dos personagens envolvidos no ataque a Ícara, na cidade de Pompeia, local onde ocorre uma sequência de crimes afetando os envolvidos no massacre. O causador das mortes e paralisias é descrito como o mago Rafa, sacerdote de uma seita cartaginesa adoradora do deus Baal e possuidor de poderes ocultos. Após Rafa fugir de Pompeia, Alix freta um navio romano e inicia uma perseguição ao mago, movimento que o leva a um porto cartaginês localizado na costa atlântica da África.

Tal como a conhecida revista Tintin de Hergé, Alix representa uma das grandes expressões dos quadrinhos franco-belgas e do gênero de quadrinhos históricos sendo, para alguns, a face europeia do Príncipe Valente. A cuidadosa ambientação histórica, a preocupação com a apresentação de notas explicativas, a qualidade (e até o excesso) dos textos e as constantes intervenções do 
narrador, entre outros aspectos, favorecem o recurso ao trabalho de Jacques Martin para o ensino de História, especialmente, de História Antiga.

Nas primeiras páginas da HQ o leitor entra em contato com a baía de Pompeia no séc. I a.C. e com os refinamentos da vida nos grandes palácios romanos da cidade (alimentos, arquitetura, escultura, música etc.), criando uma bela ambientação histórica para a história. Durante o encontro de Gallas com Alix, o texto apresenta um flashback, recurso utilizado para inserir o tema das guerras púnicas e descrever o massacre de Ícara pelos romanos. Como visto, os quadrinhos contribuem para a identificação de aspectos da vida social de comunidades do passado, permitindo ao professor partir dessas representações a fim de explorar o período antigo em sala de aula. Esses elementos colocam-se em evidência nos primeiros contatos com a HQ, não obstante, cabe observar outras formas de discutir esta obra.

Alberto Pinto considera que Martin utilizou-se do discurso colonial em sua representação da África e dos africanos. Para o historiador, esse aspecto da obra se apresenta na nudez dos africanos subsaarianos, na ausência de atividades de trabalho dos personagens africanos, no tribalismo, isto é, na identificação de que os africanos vivem em tribos e estas estão, de forma constante, em conflito, e na própria presença de personagens estereotipados como o feiticeiro e o escravo resgatado. Para Pinto, essa inexatidão histórica só pode ser entendida em Alix como uma reminiscência da classificação negativista da animalização/zoomorfização dos africanos. O autor afirma que

Para vingar Ícara, os cartagineses de Garra Negra servem-se, portanto, não apenas da zoomorfização, do "tribalismo" e do "belicismo" dos africanos, mas também do seu "animismo" ou da sua "filosofia primitiva", que o olhar ocidental confunde com a diabolização das suas crenças e o carácter oculto das suas ciências, consideradas "magias" ou "feitiços". (Pinto, 2010, p.89)

Um dos elementos mais interessantes discutidos por Alberto Pinto sobre essa HQ de Martin é a presença de relatos fantasistas acerca dos mistérios do continente africano ao longo da narrativa. Consoante o autor, Martin fez uso de uma das interpretações do Périplo de Hanão, narrativa da viagem realizada por um rei de Cartago (por volta da primeira metade do século V a.C.) "para além das colunas de Hércules" com vista a fundar cidades ao longo da costa ocidental do continente africano, e entre os elementos fantasiosos do quadrinho estão a referência a uma floresta densa e verdejante; a um enorme gorila; 
a guerreiros quase nus, armados de escudo e zagaia, envergando na cabeça toucados emplumados, evidenciando no corpo braceletes e gargantilhas de marfim; e a um crocodilo.

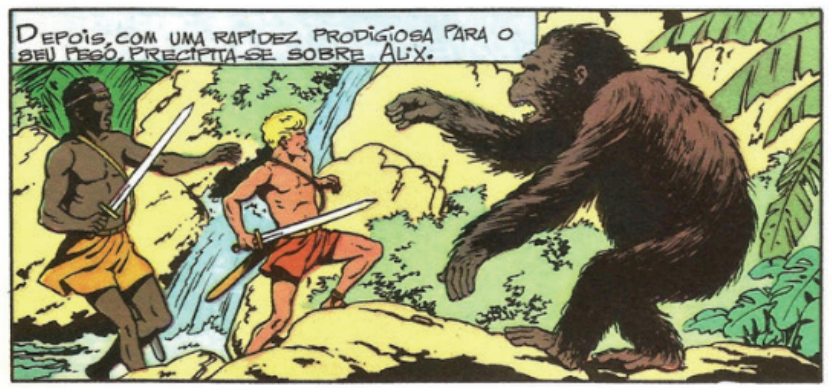

Figura 5 - Cena do volume Garra Negra. Alix na selva africana é acompanhado por um nativo e enfrenta um gorila.

Guardadas as particularidades, os elementos destacados por Alberto Pinto em Alix também se apresentam em Tintim na África/Tintim no Congo, aventura publicada pela primeira vez em junho de 1930 por Hergé. Tintim é um jovem jornalista belga que viaja pelo mundo acompanhado de seu cão Milu. No texto de 1930 viaja ao Congo, país que à época era colônia da Bélgica. Representando a África e os africanos mediante estereótipos colonialistas, presentes nas vestimentas, nas armas, na constante referência a animais selvagens, na advertência de Tintim sobre a preguiça dos africanos, na organização tribal, nas práticas de feitiçaria - tidas claramente como charlatanice - e, em especial, no recorrente discurso de bondade e desenvolvimento dos brancos, algo a ser buscado pelas tribos da África, a obra de Hergé reforça a necessidade de problematizarmos as HQs como produto de seu tempo, isto é, de o ensino de História levar em consideração a historicidade do discurso presente na HQ.
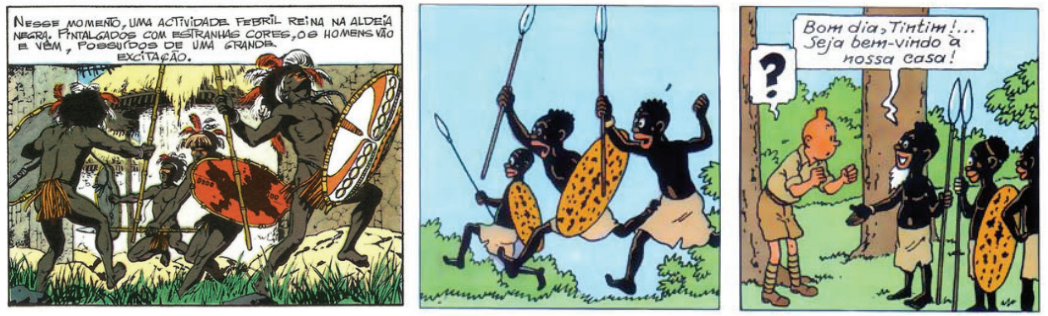

Figura 6 - Cenas tribais em Alix (esquerda) e Tintim (direita). 
A Turma da Mônica, de Maurício de Sousa, uma das histórias em quadrinhos mais bem-sucedidas do Brasil, tem a coleção Você sabia? voltada para datas comemorativas e temas transversais. Como exemplo de temáticas abordadas nesses volumes, citamos: "Índios", "Jogos Olímpicos”, "Meio Ambiente”, "Trânsito", "Abolição da escravatura", "Descobrimento da América”, "Folclore" e "Independência". A coleção carrega o selo de obra recomendada para trabalhos escolares e assume o lema "aprenda com história em quadrinhos e passatempos”. Assim, mais do que ambientada e fornecendo ideias sobre o passado, ou abordando personagens históricos, a coleção se propõe a ensinar. Para considerações, destacamos o volume que versa sobre o "Descobrimento da América”.

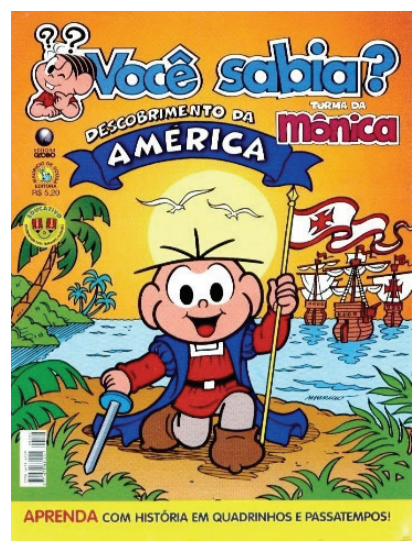

Figura 7 - Capa da edição Descobrimento da América, da coleção "Você Sabia?", de Maurício de Sousa.

Neste, Cebolinha aparece como Cristóvão Colombo e é o protagonista da história. A ênfase no personagem é reforçada na primeira página da HQ, que tem início com o nascimento de Colombo em 1451. Na mesma página, o discurso de que o personagem nasceu inclinado à navegação aparece em dois quadros, quando Cebolinha prefere um barco ao patinho de madeira e, nas palavras do narrador, "desde cedo, Colombo já pensava no mar e em navegar".

A história trata da presença de Colombo em Portugal, de seu casamento com Felipa Moniz de Perestrelo, de seus estudos das rotas marítimas, da proposta da esfericidade da Terra, da rivalidade entre Portugal e Espanha sobre o ultramar, das especiarias, da expulsão dos mouros da Península Ibérica, dos 
perigos enfrentados nas viagens marítimas, dos instrumentos de navegação, da chegada de Colombo à América e de seu retorno à Espanha. O texto caracteriza-se por seu caráter didático, apresentando termos da época, como "mouros", "mar Tenebroso", "Catai" e "Cipango", seguidos de notas explicativas. Além disso, entre as partes I e II da história o texto traz passatempos educativos e uma página apresentando os principais personagens (Colombo, Felipa Moniz e os Reis Católicos).

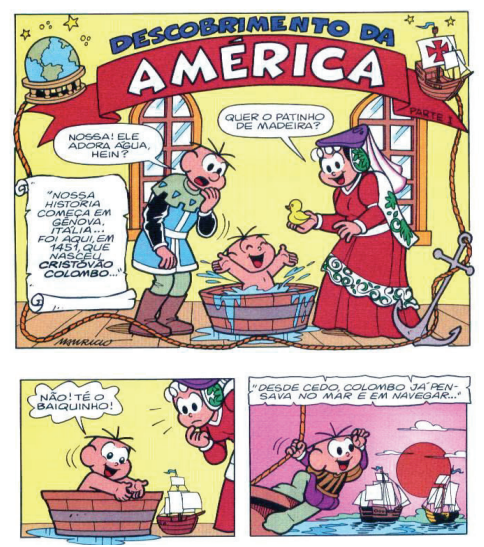

Figura 8 - Cenas do volume Descobrimento da América.

As contribuições dessa história em quadrinho e da coleção para o ensino de História são inúmeras, mostrando-se uma forma de aproximar o estudante de uma temática chave da constituição do mundo moderno. Essa aproximação, como indicado, não ocorre por uma história apenas ambientada no passado quatrocentista, pois o texto se propõe a contar a história do Descobrimento da América por Cristóvão Colombo fazendo uso de personagens clássicos do universo da Turma da Mônica, como Cebolinha, Mônica, Cascão e Bidu. Ao ler a $\mathrm{HQ}$, em especial no $7^{\circ}$ ano do Ensino Fundamental, o jovem aluno terá contato, por exemplo, com uma cuidadosa representação das caravelas e dos instrumentos de navegação, elementos técnicos fundamentais para as navegações do período, além de ler sobre as diferentes rotas marítimas para as Índias e sobre os perigos e crenças que a época tinha sobre o mar.

No entanto, cabe ao historiador problematizar a construção da narrativa histórica presente na HQ. No caso, a história concentra suas atenções no personagem Cristóvão Colombo, partindo de seu nascimento e de sua infância, 
tratados como indicadoras do futuro navegante. A HQ, por mais que contextualize personagens, termos e instrumentos, reforça uma narrativa histórica dos grandes homens e uma "ilusão biográfica" (Pierre Bourdieu), elementos que sofreram profunda revisão desde meados do século passado na historiografia. Contrastando com obras citadas anteriormente, como Cumbe e Povos Indígenas, a HQ Descobrimento da América não abre espaço para a problematização dos diferentes personagens comuns que atuaram nas navegações, da chegada dos europeus ao Novo Mundo, do contato entre europeus e ameríndios e das consequências dessa relação, nem mesmo do termo "Descobrimento".

Ao apontar essas questões, não temos o interesse de insinuar que as HQs devem se pautar pelos parâmetros acadêmicos da História ou de qualquer outra área. Os quadrinhos são o espaço do lúdico e sua narrativa, tal como o cinema, envolve uma estrutura diferente dos livros de História tradicionais. Não obstante, o caso particular analisado, mesmo sendo uma HQ de qualidade, com clara pesquisa dos elementos históricos abordados e criada sob perspectiva educacional, reforça a necessidade de o professor atuar como mediador no trabalho com tal linguagem, problematizando o discurso histórico presente na HQ. Cabe ao profissional que escolhe trabalhar com esse texto levar em consideração as diferentes histórias possíveis sobre o processo de Descobrimento, chegada ou conquista da América, mostrando aos alunos que a história em quadrinhos traz uma versão desses acontecimentos. Além disso, o exemplo da coleção Você Sabia? permite ao historiador lembrar que o discurso historiográfico presente no meio acadêmico é apenas um entre vários outros sobre o passado, sejam eles presentes nos filmes, nas minisséries ou nos quadrinhos.

O problema da relação História e Biografia, que se apresenta no texto da Turma da Mônica, mostra-se ainda mais central em obras de cunho biográfico, autobiográfico ou semiautobiográfico, como Che, Persépolis, Maus e Gen: pés descalços. Maus, de Art Spielgman, a primeira HQ a ganhar o prêmio Pulitzer de Literatura (1992), é talvez o principal exemplo desse gênero e conta a história de um judeu polonês sobrevivente ao holocausto nazista. Para a presente reflexão, escolhemos trabalhar com Gen: pés descalços, obra de Keiji Nakazawa, inicialmente lançada entre 1972 e 1973, história 
autobiográfica que relata a juventude do jovem Gen no contexto dos ataques de Hiroshima e Nagasaki.

Com claros objetivos pacifistas, Gen: pés descalços aborda os horrores da guerra e critica as ações norte-americanas e a política militarista japonesa, trazendo uma narrativa que destaca elementos cotidianos vividos no cenário do conflito, como as condições socioeconômicas e alimentares, o clima de tensão com as sirenes que indicavam o bombardeio, os locais de abrigo e as mortes que passavam a fazer parte do dia a dia de todas as faixas etárias. De forma muito marcante, o quadrinho explora a destruição gerada pelas bombas atômicas por meio de corpos desfigurados, cenários arrasados e da comovente perda dos familiares do protagonista.

A obra trata de uma temática deveras presente em filmes, revistas, séries de TV, ou mesmo em outros quadrinhos, como Kaput, Era uma vez na França, Adolf e Maus, e por esse motivo pode ser explorada como uma das narrativas possíveis dos acontecimentos do final da Segunda Guerra Mundial. Num plano específico, mostra-se interessante contrastar os diferentes discursos sobre a guerra presentes, por exemplo, em Maus e Gen: pés descalços, duas obras que abordam o sofrimento durante o conflito mundial. Além disso, consideramos que o texto de Nakazawa contribui diretamente para a problematização das consequências da guerra, do papel do nacionalismo como uma das causas da guerra e, paralelamente, para a promoção de valores pacifistas.

Com viés diferente, mas também relacionada à Segunda Guerra Mundial, Adolf (2006) traz para o primeiro plano as múltiplas narrativas sobre os acontecimentos. A história foi escrita e ilustrada por Osamu Tezuka (1928-1989), considerado o maior quadrinista japonês de todos os tempos, e se estrutura em torno do repórter japonês Sôhei Tôge e de três personagens de nome Adolf: Adolf Kaufmann, filho de um diplomata alemão e uma mãe japonesa; Adolf Kamil, filho de padeiros judeus; e Adolf Hitler. O texto tem início nas Olimpíadas de Berlim (1936), quando Tôge faz a cobertura dos jogos e inicia uma investigação sobre as possíveis origens judias de Hitler. Outro núcleo da trama envolve os demais Adolf, amigos que moram na cidade de Kobe e, pelo fato de um deles ser judeu, enfrentam diferentes dificuldades para manter a amizade, chegando a ser separados pela guerra. 

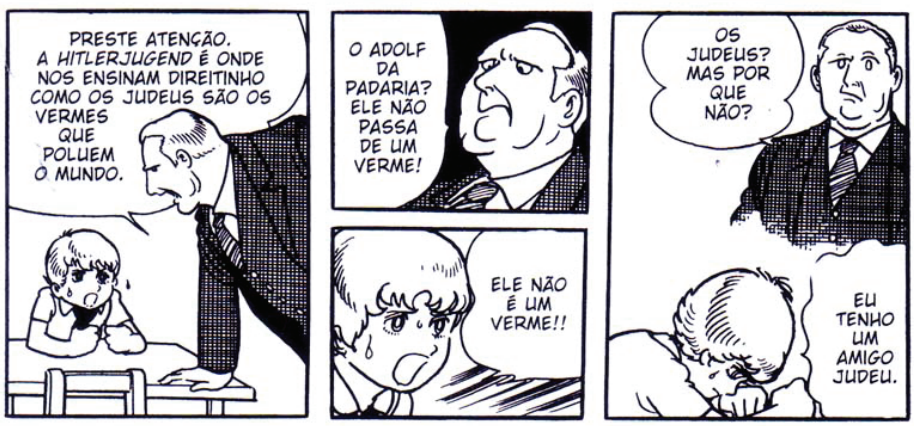

Figura 9 - Cena de Adolf. O jovem Adolf, filho de pai alemão e mãe japonesa, é pressionado a assumir posições antissemitas pela direção da escola. (Sentido da leitura: da direita para a esquerda.)

Adolf caracteriza-se pelo cuidado com a apresentação da ambientação histórica e por fornecer tabelas distribuídas pelo texto com indicações dos acontecimentos que se passam no período da trama, elementos que auxiliam o trato dos docentes com o mangá. Além disso, a obra aborda temas como a propaganda nazista, o preconceito e a perseguição aos judeus, a atuação de pessoas comuns no desenvolvimento do nazismo, e o antissemitismo fora da Alemanha, aspectos diretamente relacionados às aulas de História sobre meados do século XX, mas que também podem ser explorados em discussões temáticas. Não obstante, consideramos que a principal singularidade de Adolf está em propor uma visão de meados do século passado com base em três personagens distintos, articulando suas trajetórias em torno da guerra. Nas últimas décadas, com o chamado "ressurgimento da narrativa" (Lawrence Stone), a História vem buscando explorar academicamente outras maneiras de construção textual; pensamos que Adolf constitui interessante via dessas orientações para o trabalho em sala de aula.

Para finalizar, citamos uma última HQ: $O$ mundo de Aisha. A revolução silenciosa das mulheres no Iêmen (2015), de Ugo Bertotti (roteiro e arte) e Agnes Montanari (entrevistas e fotografia). Inserida no gênero jornalismo em quadrinhos, a obra explora a experiência de Montanari no Iêmen, especificamente em relação à vida das mulheres iemenitas, marcadas pelo uso do niqab (véu negro que cobre o rosto e deixa somente os olhos descobertos). O texto aborda a sociedade patriarcal, o peso da religião e das tradições e a vida cotidiana no país, tendo como base o olhar de mulheres comuns. 
Apesar da crescente presença do mundo muçulmano nas mídias, em geral associado a casos de extremismo e intolerância, pouco se sabe sobre ele, sendo comum encontrar preconceitos e visões estereotipadas que prejudicam a compreensão do outro. No campo da História a situação não é radicalmente distinta, nem mesmo nos livros didáticos o mundo muçulmano aparece de forma satisfatória, pelo contrário, tende a aparecer para situar o surgimento do Islamismo na Idade Média e nos conflitos entre árabes e israelenses. Nesse universo de lacunas, o Iêmen e suas mulheres passam ainda mais despercebidos, por mais que telejornais explorem as misteriosas mulheres muçulmanas com trajes exóticos para o olhar Ocidental. A HQ em questão, em três histórias, aborda temas como a violência doméstica, as dificuldades das mulheres no mercado de trabalho, a pressão para o casamento e uma série de problemas cotidianos. Em O mundo de Aisha o leitor entra em contato com o mote "a revolução silenciosa das mulheres no Iêmen”, subtítulo da obra que expressa a importância da atuação das personagens na luta para que as próximas gerações não passem pelos mesmos obstáculos e preconceitos que elas enfrentaram.

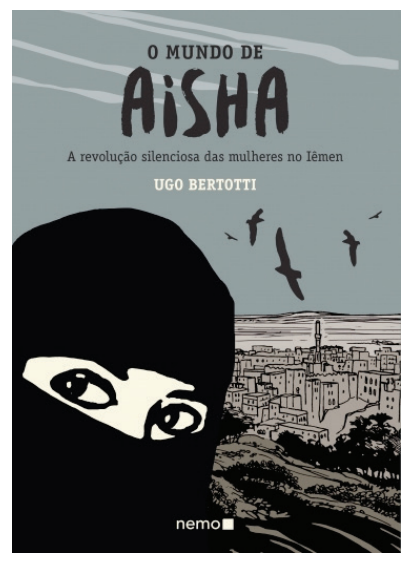

Figura 10 - Capa de O mundo de Aisha (2015).

Consideramos que a obra é de suma relevância para o trabalho no ensino de História. As temáticas envolvidas justificam-se por si só, tanto no campo específico da História como para a discussão de temas transversais. Os desafios enfrentados pelas mulheres no Brasil, também relacionados ao machismo, à violência e às barreiras ainda existentes no mercado de trabalho, permitem contrastes com a narrativa sobre o Iêmen. Acrescenta-se que $O$ mundo de 
Aisha não se propõe a avaliar ou a julgar a vida das personagens, permitindo ao leitor compreender o uso do niqab, por exemplo, de maneira mais reflexiva. Por fim, a história tem como estrutura as múltiplas narrativas acerca de um eixo comum, o que constitui mais um viés que pode ser explorado pelos professores de História.

\section{CONSIDERAÇÕES FINAIS}

O fato de serem lúdicos e ficcionais não impede que o historiador utilize quadrinhos no ensino de História. Os antigos preconceitos e resistências quanto à presença de tais obras no ambiente escolar foram, em grande parte, superados, e os 10 anos de publicações de quadrinhos pelo PNBE têm contribuído diretamente para essa superação. Os estudos da área do ensino têm explorado a importância da inserção de variadas linguagens nas salas de aula, e as HQs constituem linguagem singular através da qual fatos, épocas e ideias são vividos por personagens, dando escala textual e imagética a tais elementos. Além disso, os quadrinhos promovem a leitura, a interpretação e a imaginação, aspectos diretamente relacionados às aulas de Linguagens, mas também fundamentais para as Humanidades e, especificamente, para a História.

Buscamos demonstrar ao longo deste artigo que as HQs podem ser mais do que apenas ilustrações para a aula de História. Exemplos como Xingu, Povos Indígenas e Cumbe expressam que alguns quadrinhos assumem papel importante na construção do passado, reescrevendo a própria história a partir do olhar de grupos até então alijados das narrativas fundadas na perspectiva do colonizador ou numa concepção de história política-institucional. Paralelamente, destacamos que casos como Alix, Tintim e Você sabia? convidam o professor de História a atentar aos estereótipos étnicos que se estruturam e se reafirmam por intermédio dos quadrinhos, às tradicionais histórias fundadas nos grandes homens e nos grandes feitos, e à historicidade do discurso presente nas HQs.

Buscamos apresentar diferentes HQs de gêneros e décadas distintas, pontuando possíveis problemas para a discussão e possíveis utilizações no ensino de História, em especial por eixos como: História e Biografia, História e Narrativa, História vista de baixo, Violência e Estereótipos, entre outros. O mercado editorial de HQs é crescente no país, e o significativo número e 
variedade de títulos nacionais e estrangeiros, impressos e on-line, possibilita que o professor tenha os quadrinhos como recurso pedagógico capaz de promover a leitura, a imaginação e, também, o conhecimento histórico. Sabemos que as reflexões apresentadas são, sobretudo, sugestões deveras parciais, relacionadas a inquietações um tanto particulares; assim, cabe aos leitores destas breves palavras também procurar na nona arte suas próprias questões e, quiçá, perceber novas maneiras de trabalhar com quadrinhos em sala de aula, seja nos domínios de Clio, seja nas demais áreas do ensino.

\section{REFERÊNCIAS}

BARBOSA, Alexandre. História e Quadrinhos: a coexistência da ficção e da realidade. In: VERGUEIRO, Waldomiro; RAMOS, Paulo (Org.) Muito além dos quadrinhos: análise e reflexões sobre a 9a arte. São Paulo: Devir, 2009. p.103-112.

BONIFÁCIO, Selma de F. História e (m) Quadrinhos: análises sobre a História ensinada na arte sequencial. Dissertação (Mestrado em Educação) - Universidade Federal do Paraná. Curitiba, 2005.

BONIFÁCIO, Selma de F.; CERRI, Luís F. Histórias em quadrinhos: conhecimento histórico e comunicação de massa no espaço escolar. In: SIMPÓSIO NACIONAL DE HISTÓRIA, 23., 2005, Londrina. Anais... p.1-8.

BOURDIEU, Pierre. A ilusão biográfica. In: FERREIRA, Marieta de M.; AMADO, Janaina (Org.) Usos \& abusos da história oral. 8.ed. Rio de Janeiro: Ed. FGV, 2006, p.183-191.

EISNER, Will. Quadrinhos e arte sequencial. São Paulo: Martins Fontes, 1999.

FONSECA, Selva G. Didática e prática de Ensino de História. Campinas: Papirus, 2003.

Ensino de História: diversificação de abordagens. Revista Brasileira de História, Dossiê História em Quadro-Negro, São Paulo, v.9, n.19, p.197-208, set. 1989/fev. 1990. Disponível em: http://www.anpuh.org/revistabrasileira/view?ID_ REVISTA_BRASILEIRA=22.

FRONZA, Marcelo. O significado das Histórias em Quadrinhos na Educação histórica dos jovens que estudam no Ensino Médio. Dissertação (Mestrado em Educação) Universidade Federal do Paraná. Curitiba, 2007.

MOYA, Álvaro. História das histórias em quadrinhos. Porto Alegre: L\&PM, 1986.

NEBIOLO, Gino et al. Los comics de mao. Barcelona: Gustavo Gili, 1976.

PINTO, Alberto. A retórica colonial na narrativa histórica sobre antiguidade: "Garra Ne- 
gra", de Jacques Martin. Revista rascunhos culturais, Coxim, MS: Universidade Federal do Mato Grosso do Sul, v.2, n.3, p.75-101, jan./jun. 2011. Disponível em: http://revistarascunhos.sites.ufms.br/files/2012/07/3ed_artigo_5.pdf; Acesso em: 15 jul. 2016.

RAMA, Ângela; VERGUEIRO, Waldomiro (Org.) Como usar as histórias em quadrinhos em sala de aula. São Paulo: Contexto, 2014.

RAMOS, Paulo. Revolução do gibi: a nova cara dos quadrinhos no Brasil. São Paulo: Devir, 2012.

ROCHA, Helenice. Linguagem e novas linguagens: pesquisa e práticas no ensino de história. In:___ MAGALHÃES, Marcelo; GONTIJO, Rebeca (Org.) O ensino de história em questão: cultura histórica, usos do passado. Rio de Janeiro: Ed. FGV, 2015. p.97-119.

ROSENSTONE, Robert A. A história nos filmes: os filmes na história. São Paulo: Paz e Terra, 2015.

SANTOS NETO, Elydio dos; SILVA, Marta Regina P. da (Org.) História em Quadrinhos e Educação: formação e prática docente. São Bernardo do Campo: Ed. Umesp, 2011.

; . (Org.) Histórias em Quadrinhos e Práticas educativas: o trabalho com universos ficcionais e fanzines. São Paulo: Criativo, 2013.

.; __ (Org.) Histórias em Quadrinhos e Práticas educativas: os gibis estão na escola, e agora? São Paulo: Criativo, 2015.

TATSUBÔ, Fábio. Utilização do mangá em sala de aula. In: LUYTEN, Sônia B. (Org.) Cultura pop japonesa: mangá e animê. São Paulo: Hedra, 2005. p.119-124.

VERGUEIRO, Waldomiro. Uso das HQS no ensino. In: RAMA, Ângela; VERGUEIRO, Waldomiro (Org.) Como usar as histórias em quadrinhos em sala de aula. São Paulo: Contexto, 2014. p.7-30.

A pesquisa em quadrinhos no Brasil: a contribuição da universidade. In: LUYTEN, Sônia B. (Org.) Cultura pop japonesa: mangá e animê. São Paulo: Hedra, 2005. p.15-26.

VERGUEIRO, Waldomiro; RAMOS, Paulo (Org.) Quadrinhos na Educação: da rejeição à prática. São Paulo: Contexto, 2009.

VILCHES, Geraldo. Breve história del cómic. Madrid: Nowtilus, 2014.

VILELA, Marco Túlio R. A utilização dos quadrinhos no ensino de História: avanços, desafios e limites. Dissertação (Mestrado em Educação) - Universidade Metodista de São Paulo. São Bernardo do Campo, 2012.

. Os quadrinhos na aula de História. In: RAMA, Ângela; VERGUEIRO, Waldomiro (Org.) Como usar as histórias em quadrinhos em sala de aula. São Paulo: Contexto, 2014. p.105-129. 


\section{Publicações em quadrinhos}

BERTOTTI, Ugo (roteiro e arte); MONTANARI, Agnes (entrevistas e fotografia). O mundo de Aisha: a revolução silenciosa das mulheres no Iêmen. São Paulo: Nemo, 2015.

D'SALETE, Marcelo. Cumbe. São Paulo: Veneta, 2014.

MACEDO, Sérgio. Povos indígenas. São Paulo: Zarabatana, 2012.

. Xingu. São Paulo: Devir, 2008.

MARTIN, Jacques. Garra Negra. Lisboa: Edições 70, 1987.

. Garra Negra. Lisboa: Edições Asa, 2010.

NAKAZAWA, Keiji. Gen: pés descalços. 10v. São Paulo: Conrad, s.d.

SACCO, Joe. Área de segurança Gorazde: a Guerra na Bósnia Oriental (1992-1995). São Paulo: Conrad, 2001. . Uma história de Sarajevo. São Paulo: Conrad, 2005. . Notas sobre Gaza. São Paulo: Quadrinhos na Cia, 2010. . Palestina: na Faixa de Gaza. São Paulo: Conrad, 2005. . Palestina: uma nação ocupada. São Paulo: Conrad, 2000.

SOLTANI, Amir; BENDIB, Khalil. O Paraíso de Zahra. Rio de Janeiro: LeYa, 2011.

SOUSA, Maurício de. Descobrimento da América. São Paulo: Globo, s.d. (Coleção "Você Sabia?").

TEZUKA, Osamu. Adolf. São Paulo: Conrad, 2006.

\section{NOTA}

${ }^{1}$ A questão das práticas de ensino relativas aos quadrinhos tem como principais obras: SANTOS NETO; SILVA $(2011 ; 2013 ; 2015)$ e RAMA; VERGUEIRO (2004). No caso específico da História, a presença das HQs no ensino passa despercebida nos principais livros da área, sendo exemplo marcante a obra Didática e Prática de Ensino de História (FONSECA, 2003), na qual o capítulo "A incorporação de diferentes fontes e linguagens no ensino de História” não faz menção aos quadrinhos. Acrescente-se que a discussão das HQs no ensino de História é expressão de uma problemática maior que são as "(novas) linguagens no ensino de História", debate marcado, em linhas gerais, por relatos de experiência docente (FONSECA, 1989/1990; ROCHA, 2015). Entre os títulos de História relacionados ao uso dos quadrinhos no ensino, indicamos: BONIFÁCIO; CERRI, 2005; BONIFÁCIO, 2005; FRONZA, 2007; VILELA, 2012.

Artigo recebido em 28 de novembro de 2016. Aprovado em 16 de janeiro de 2017. 